\title{
Environmental Regulations and the Welfare Effects of Job Layoffs in the United States: A Spatial Approach
}

\author{
By Nicolai V. KuminofF, TOdD Schoellman, AND Christopher Timmins*
}

APRIL 2015

This article develops welfare-consistent measures of the employment effects of environmental regulation. Our analysis is based on a microeconomic model of how households with heterogeneous preferences and skills decide where to live and work. We use the model to examine how job loss and unemployment would affect workers in Northern California. Our stylized simulations produce earnings losses that are consistent with empirical evidence. They also produce two new insights. First, we find that earnings losses are sensitive to business cycle conditions. Second, we find that earnings losses may substantially understate welfare losses once we account for the fact that workers may have to commute further or live in a less desirable community after losing a job.

JEL classification: D61, J6, Q52, R2.

Key words: environmental regulation, employment effects, layoffs, consumer welfare, sorting.

\footnotetext{
* Kuminoff: Arizona State University, Dept. of Economics, Tempe, AZ 85287 (e-mail: kuminoff@asu.edu). Schoellman: Arizona State University, Dept. of Economics, Tempe, AZ 85287 (e-mail: todd.schoellman @ gmail.com). Timmins: Duke University, Dept. of Economics, Durham, NC 27708 (e-mail: timmins@econ.duke.edu). We are grateful for helpful comments from Scott Farrow, Dan Phaneuf, V. Kerry Smith, EPA staff, two anonymous referees, Charlie Kolstad, and participants at EPA workshops in May 2012 and October 2012 and the AERE summer 2013 workshop. We are grateful to Suzanne Leonard for outstanding editorial assistance.
} 


\section{INTRODUCTION}

Many federal regulations have direct or indirect effects on employment. Some evaluations of U.S. government regulations include estimates of these effects, measured as the number of jobs that will be created or lost due to the regulation. A literature has emerged that attempts to measure the costs or benefits of these employment changes, focusing primarily on foregone earnings for workers who experience unemployment or re-employment at different wages (e.g., Couch and Placzek 2010, Walker 2013).

However, the majority of job searches are inherently spatial. ${ }^{1}$ That is, a worker's job location limits where he can live, and his house location limits where he can work. These constraints link the housing and labor markets in ways that influence the spatial mobility of the labor force. For example, according to the American Housing Survey ${ }^{2}$, "new job or job transfer" is the second most frequently cited reason for moving out of a former dwelling. Likewise, "convenient to job" is the most frequently cited reason for selecting a new neighborhood. These statistics suggest that it may be important to consider the effects of layoffs on spatial mobility. If an unemployed worker's best job offer is far from his house, then he may decide to move. If he perceives the quality of life to be lower (higher) in his new neighborhood than in his old neighborhood, then he may expe-

\footnotetext{
${ }^{1}$ Approximately $75 \%$ of U.S. workers report that they spend no time telecommuting (Noonan and Glass, 2012).

${ }^{2}$ The data can be accessed from http://www.census.gov/programs-surveys/ahs.html.
} 
rience a welfare loss (gain) in addition to any change in earnings.

The purpose of this article - which is part of a symposium on "Unemployment, Environmental Regulation, and Benefit-Cost Analysis"3 — is to broaden the notion of the employment effects of regulations to account for how layoffs affect people's decisions about where to live and work. This has potentially important welfare implications if people relocate to neighborhoods that they like less or if they face longer commutes. We use a new equilibrium sorting model to develop a framework for estimating the welfare costs of layoffs caused by regulations that accounts for these spatial effects as well as the more typical effects of lost earnings.

Equilibrium models of residential sorting use the logic of revealed preferences to explain how households sort themselves across neighborhoods based on their incomes and tastes for housing and amenities provided by those neighborhoods (Kuminoff, Smith, and Timmins 2013). A few recent studies have incorporated the interaction between labor market choices and housing choices into this literature (Kuminoff 2010, Bishop 2011, Mangum 2012). We use the model from Kuminoff (2010) to show how an analyst's estimate of the number of layoffs that will be caused by a regulation can be translated into an economic measure of consumer welfare that accounts for the costs of unemployment, changes in job pro-

\footnotetext{
${ }^{3}$ The other articles are Smith (2015), which provides an introduction to the symposium; Bartik (2015), which examines the social value of job losses and its impact on the overall costs of U.S. environmental regulations; and Rogerson (2015), which discusses how dynamic general equilibrium methods used to evaluate macroeconomic policies can be used to evaluate environmental regulations.
} 
spects, and changes in where people live and work and how far they commute. We apply the model to data on working households in Northern California.

Our findings suggest that analysts should be wary of interpreting changes in workers' earnings as welfare effects of layoffs or newly created jobs. Changes in earnings may understate or overstate welfare effects. The direction and magnitude of the bias depend on whether the workers who experience layoffs end up with housing options, commuting options, job options, and access to local public goods that they perceive to be more or less desirable than their original locations. We also find that earnings losses are sensitive to business cycle conditions.

This article occupies a middle ground between Bartik (2015), which presents a partial equilibrium model, and Rogerson (2015), which presents a general equilibrium model. Our approach is related to Bartik (2015) in that we both consider the costs associated with transitioning from job loss to new employment. However, we focus on the spatial component of this process, while Bartik focuses on factors that reduce the value of non-work time. Both articles consider worker-specific factors that might affect the duration of unemployment, such as industry, occupation, income, age, and house location. This introduces an important source of heterogeneity that is more difficult to address in the general equilibrium models considered by Rogerson (2015). In contrast to Rogerson (2015), we do not model working households as forward-looking dynamic decision-makers. Nor do we model impacts on firms, adjustments to equilibrium prices or wages, or the wel- 
fare costs of collecting public funds through taxation to pay for unemployment insurance.

In the remainder of this article, we first provide an overview of the equilibrium sorting model. Then, using data for working households in Northern California, we demonstrate how the model could be applied. This is followed by a discussion of the implications for adapting our framework to consider specific regulations. We conclude with some caveats and suggestions for future research.

\section{OVERVIEW OF THE SORTING MODEL}

Sorting models are often used to predict the welfare effects of policies that influence the quality of life by altering the spatial distribution of public goods, such as school quality, public safety, open space, or other environmental amenities. While most applications assume the policy has no effect on wages or employment, Kuminoff (2010) models the connection between location decisions in the housing and labor markets. Households are assumed to differ in their job skills and in their preferences for local public goods, housing, and a composite private good. Job locations are assumed to differ in their wages and in their commute times to the various neighborhoods. Neighborhoods differ in the public goods they provide and in the price of housing. Each household is assumed to weigh its options before choosing the job-house combination that maximizes its utility. 
We consider a potential regulation that is expected to improve environmental quality but at the cost of inducing layoffs for workers in a particular industry and geographic area. For example, a proposed regulation might target the manufacturing sector in counties designated as severe nonattainment areas for federal air quality standards. We assume the analyst has an estimate in mind for the number of layoffs that will be caused by the regulation. How would the layoffs affect consumer welfare? The equilibrium sorting approach answers this question using four steps. The first step is to characterize the microeconomic process that led the affected households to choose their current jobs and houses (i.e., before the regulation). The second step is to use information on macroeconomic conditions to predict the expected duration of the unemployment spells for the workers who lose their jobs. The third step is to predict where the unemployed workers will eventually relocate. The fourth step is to calculate the change in consumer welfare implied by the wages lost during unemployment and the adjustment costs associated with relocation. The remainder of this section describes the four steps in more detail ${ }^{4}$ and then compares the sorting model with a general equilibrium model.

\section{Step 1: Characterizing Workers' Baseline Job and Housing}

\section{Choices}

\footnotetext{
${ }^{4}$ A formal technical presentation of the model appears in Kuminoff, Schoellman, and Timmins (2013).
} 
Most Americans live in urban regions with diverse opportunities for employment and housing. Equilibrium sorting models typically focus on a single region (e.g., Bayer et al. 2011, Epple and Sieg 1999, Klaiber and Phaneuf 2010, Smith et al. 2004). The modeling process begins by dividing the region into housing communities and job locations. Communities are sometimes defined using public school district boundaries because these areas are sufficiently large to have noticeable differences in the price of housing and access to local public goods. Public goods may include services provided through tax revenue, such as school quality, as well as environmental amenities influenced by regulatory activity, such as air quality. Job locations are often defined as metropolitan areas (e.g., San Jose, Oakland). Conditional on skill, a worker may be compensated differently in different job locations due to spatial variation in regulation, tax rates, local cost-ofliving adjustments, unionization, and other factors that affect the local demand for labor.

Working households are assumed to have perfect information about the spatial landscape (e.g., they are assumed to know the levels of air quality and school quality in every school district). They then evaluate the feasible job-house locations and select the one that maximizes their utility. A household's utility depends on its consumption of private goods (including housing), its access to local public goods in its home community, and the amount of time the household's primary earner must spend commuting. Following one of the main branches of 
the literature, we use a parametric model for utility that assumes a constant elasticity of substitution (CES) between public and private goods (e.g., Epple and Sieg 1999, Sieg et al. 2004, Kuminoff 2010). ${ }^{5}$ This utility function implicitly defines the labor supply and housing demand functions that underlie the equilibrium wage function in the labor market and the equilibrium price function in the housing market.

We observe the house prices and local public goods in different communities; the wages workers earn in their chosen jobs; and the commute times between communities and job locations. Our econometric model estimates the preferences of households for private consumption and public goods, and the skills of workers that rationalize these observed choices and prices as equilibrium outcomes in the market. This process involves characterizing each worker's job opportunities.

The primary earner of each household is assumed to possess skills that determine the wages he would earn in each job location. Some skills, such as a worker's education or occupation, can be measured using U.S. Census public use micro data files. ${ }^{6}$ We can use these measured skills to predict the worker's wage in each job location. The difference between the predicted and actual wage at the

\footnotetext{
${ }^{5}$ Formally, the indirect utility for household $i$ from living in community $j$ and working in labor market $k$ is defined as $V_{i j k}=\left\{\alpha_{i}\left(q_{i j}\right)^{\rho}+\left[\exp \left(\frac{y_{i k}^{1-v}-1}{1-v}-\phi_{i} t_{j k}\right) \exp \left(-\frac{\beta p_{j}^{\eta+1}-1}{1+\eta}\right)\right]^{\rho}\right\}^{\frac{1}{\rho}}$, where $q_{i j}=\gamma_{i 1} g_{1 j}+\cdots+\gamma_{i N-1} g_{N-1 j}+\xi_{j}$ is a linear index of local public goods provided by community $j$ as perceived by household $i$; $y_{i k}$ is the income earned when the primary earner of the household works in labor market $k ; t_{j k}$ is a measure of the time required to commute between $j$ and $k ; p_{j}$ is a measure of the price of housing, and $\alpha, \beta, \gamma, \xi, \eta, \nu, \phi$, and $\rho$ are preference parameters recovered during the estimation. See Kuminoff (2010) for details.

${ }^{6}$ The files are available from http://www.census.gov/acs/www/data documentation/public use microdata_sample/
} 
worker's chosen job location reveals the importance of the worker's skills that are not measured in the Census. Similarly, information on housing prices, household income, and access to local public goods is used to infer the strength of a household's preferences for public and private goods. For example, all else constant, a household that chooses to spend a larger fraction of its income in order to live in a community with good air quality is revealed to have relatively strong preferences for air quality. ${ }^{7}$

\section{Step 2: Predicting the Expected Duration of Unemployment Spells}

We mimic the experience of losing a job by removing the primary earner's current job location from his set of feasible locations. Forcing unemployed workers to work in a new metropolitan region allows us to evaluate the potential for spatial migration in the labor market to influence the welfare effects of layoffs. ${ }^{8}$

The transition to a new job takes time. The worker must prepare a resume, search for vacancies, and go through interviews. ${ }^{9}$ The probability that a newly unemployed worker will find a job within a given amount of time can be modeled using the actual job-finding experiences of recently unemployed workers in the

\footnotetext{
${ }^{7}$ By allowing working households to have heterogeneous preferences and skills, our model generalizes the Rosen (1979) and Roback (1982) model of equilibrium in the housing and labor markets, which assumes that working households are homogeneous.

${ }^{8}$ We assume that when a worker is looking for a job, he collects unemployment insurance, which is consistent with current U.S. policy.

${ }^{9}$ If a prospective job is located far away, the worker may also choose to search for housing simultaneously.
} 
same industry. ${ }^{10}$ Of course, the duration of unemployment may also vary with macroeconomic conditions. More specifically, it will tend to be shorter during an economic expansion and longer during a recession.

\section{Step 3: Predicting the Worker's New Job and Housing Location}

\section{Choices}

After removing a worker's current job location from his set of feasible locations, we use his calibrated utility function to predict which of the remaining job-house locations would maximize his household's utility. Then we assign the worker to the corresponding metro area. The worker's new job may be in a different industry, but his occupation is assumed to be unchanged. This allows us to match each worker to the wages paid to other workers with similar training. ${ }^{11}$ Whether the worker's wage rises or falls at his new job also depends on his skills identified in step 1. After moving to the new job location, the worker may choose to continue to live in the community where his previous job was located. However, if the required commute time induces the worker to move to a different community, then the change in his utility will depend on his household's preferences concerning local public goods relative to the public goods provided by the new community.

\footnotetext{
${ }^{10}$ This is reported in the Current Population Survey. The data can be accessed at: http://www.census.gov/cps/data/http://www.census.gov/cps/data/

${ }^{11}$ In practice, we define occupations using 5-digit codes from the Standard Occupational Classification system. For example, the 5-digit SOC codes distinguish between five types of social scientists: economists, market and survey researchers, psychologists, sociologists, and urban and regional planners.
} 
A household may prefer the public goods provided by the new community or the household's income may rise at the primary earner's new job, but both cannot occur simultaneously. This is because the model assumes that utility must decline when a household's preferred location is removed from its choice set.

There are four caveats to our predictions concerning the worker's new job and housing location choices. First, the model focuses exclusively on the primary earner's contribution to household income. All other sources of income are assumed to be fixed, including the wages of any secondary earners in each household. ${ }^{12}$ Second, the model does not allow unemployed workers to move to lowerskill jobs in the same metro area (e.g., a machinist cannot work as a cashier). ${ }^{13}$ This is because the model does not identify a worker's second best job offer in his current job location. ${ }^{14}$ Thus, we consider two extreme scenarios-a "best-case" scenario for the worker in which he ultimately finds a new job at the same wage as his old job and in the same metro area as his old job, and a "worst-case" scenario in which the worker finds a new job in a different metro area where he is paid less and/or has to move to a neighborhood with a lower quality of life. These two scenarios define upper and lower bounds, respectively, on the welfare consequences of choosing to move to a lower-skill lower-pay job in the same metro ar-

\footnotetext{
${ }^{12}$ In order to consistently predict how the incomes of secondary earners would adjust, the model would need to be extended to depict bargaining within the household.

${ }^{13}$ This could be particularly important when considering the issue of owners v. renters. Owners may face bigger moving costs and might be willing to accept lower paying jobs to avoid leaving their homes.

${ }^{14}$ As part of a sensitivity analysis summarized in the appendix, we show how the model could be calibrated to allow workers to move to lower paying jobs in the same location if the analyst is willing to make an assumption about the reduction in wages at the new job.
} 
ea as the old job. ${ }^{15}$ Third, the model does not include search costs. If there were search costs, then it would be possible for a laid off worker-who is now forced to search — to find a higher paying job. Fourth, because a household's heterogeneous preference and skill parameters are estimated in step 1, rather than observed directly, there is some uncertainty in the model's prediction for a particular household's new job and house locations. Thus, as discussed in the next step, we report welfare effects as averages by household type (e.g., the average of welfare measures calculated for all over-40 workers who lose their jobs in the manufacturing sector in the Oakland metro area).

\section{Step 4: Calculating the Change in Consumer Welfare}

For simplicity, we assume that layoffs and any changes in environmental quality are sufficiently small to leave housing prices and wages unaffected. Thus, the change in consumer welfare can be measured using the partial equilibrium concept of equivalent variation (EV). We define $\mathrm{EV}$ as the amount of annual income one would have to give (or take from) a household before implementation of the regulation to make them as well off as they would be after the regulation, given the duration of the primary earner's unemployment spell, the wage at his new job, and any adjustments to the household's quality of life.

\footnotetext{
${ }^{15}$ The reason the "worst-case" scenario gives a lower bound is because a utility-maximizing worker who chooses to remain in the same metro area at a lower paying job must be at least as well off from that choice as he would be from choosing to move to his best job offer in a different metro area.
} 
Because the model is inherently static, it assumes that each worker's next job is his second-best choice, without considering any intervening or temporary jobs. Likewise, the model assumes that workers earn their new salaries immediately, without considering any initial period of lower salary or higher salary growth. The lack of dynamics also complicates the treatment of unemployment spells. For simplicity, we convert the wages lost during the worker's unemployment spell into an annuity, using the worker's expected lifespan and an interest rate that matches the cost of borrowing on a 30-year fixed rate mortgage. Intuitively, we are assuming that the household finances its consumption during the unemployment spell by borrowing against its house, thus spreading the temporary wage shock across the worker's expected lifespan.

Some workers who find new jobs may be underemployed. More specifically, the worker's hours worked are assumed to be fixed, but his second-best job option may be in an industry that does not allow him to fully utilize his occupational skills. ${ }^{16}$ This loss of industry-specific or job-specific human capital may cause the worker's wage to decline.

\section{Comparison with a General Equilibrium Model}

Compared to a conventional general equilibrium (GE) model of the economy, our

\footnotetext{
${ }^{16}$ We may understate the potential for underemployment by not allowing workers to change occupations. It would be interesting to know how many workers who lose their jobs because of regulation actually do change occupations.
} 
sorting framework puts more emphasis on understanding the distribution of heterogeneous wage effects and welfare effects experienced by workers, and less emphasis on aggregating these effects. For example, we can investigate the extent to which wage effects and welfare effects vary across working households based on demographic characteristics we can observe (e.g., income, occupation, industry) and estimated parameters that represent unobserved features of their human capital and preferences for public goods. The sorting model also allows us to consider the role of space-i.e., that changes in earnings and public goods may be conveyed to households through spatial adjustment. In contrast, most GE models lack a spatial dimension.

However, the flexibility allowed by our sorting model also comes at a cost. First, while it depicts interrelated behavior in multiple markets, the sorting model is a static framework that excludes GE feedback mechanisms. For example, if a particular regulation were to induce enough people to move, their migration patterns could lead to adjustments in the equilibrium housing price function, the wage function, commute times, and the provision of local public goods which, in turn, would feed back into welfare measures. In order to predict these adjustments with the sorting model we would first need to define the demand for labor, the supply of housing, and the production functions for each endogenous public good. Bayer and Timmins (2005) demonstrate that models with endogenous public goods can generate multiple equilibria, complicating ex ante analysis of pro- 
spective policies. In contrast, GE models often obtain unique equilibria by assuming households are homogeneous.

Second, in contrast to most GE models, in the sorting model, the prices of private goods are assumed to be unaffected by shocks to the housing and labor markets. Moreover, the lack of an explicit model of the firm or government means that we cannot construct measures of producer surplus, social welfare, or the deadweight loss from unemployment insurance schemes. Finally, unlike the broad class of dynamic stochastic GE models used in macroeconomics (e.g., Rogerson 2015) our sorting framework does not allow us to predict the adjustment path to a new equilibrium. Overall, these limitations suggest that the sorting framework is most appropriate for evaluating regulations that affect a small share of workers in a particular industry and study region. We provide an example in the next section.

\section{APPLYING THE MODEL TO LAYOFFS IN NORTH-}

\section{ERN CALIFORNIA}

To demonstrate the potential importance of spatial migration for the welfare effects of layoffs, we build a "layoff simulator" for Northern California and use it to predict the wage effects and welfare effects of layoffs. To focus on modeling the effects of layoffs, we do not consider a particular regulation and do not model 
changes in environmental quality. Our analysis proceeds in three steps. First, we explain how Kuminoff (2010) calibrated the microeconomic sorting model to characterize the job and housing location choices made by working households in Northern California. Second, we predict the likely duration of unemployment spells that would be experienced by workers at different stages of the macroeconomic business cycle. Third, we summarize how our estimates for wage effects and welfare effects of layoffs vary across households according to their demographic characteristics and job locations.

\section{Calibrating the Model to Working Households in Northern Cali- fornia}

First, we calibrated the model to Northern California's two main population centers - the San Francisco and Sacramento consolidated metropolitan statistical areas. ${ }^{17}$ We defined housing communities by dividing the region into 122 unified school districts and 8 job locations based on the region's 8 primary metropolitan statistical areas-PMSAs (see Figure 1). The population is concentrated around the San Francisco Bay and the city of Sacramento (as indicated by the density of census tracts in the left map in Figure 1). The set of possible location choices is defined by 268 community-PMSA combinations that, together, account for $99 \%$

\footnotetext{
${ }^{17}$ This region contains approximately 9 million people, or $3 \%$ of the U.S. population.
} 
of the working population. ${ }^{18}$

\section{$\underline{\text { Housing Prices }}$}

Housing prices were calculated from micro data on housing sales recorded by county assessors between 1995 and 2005. These data were used to calculate an index of community-specific housing prices using a procedure described in Sieg et al. (2002). The index ranges from 1.00 to 6.51, and its distribution is consistent with the conventional wisdom that housing is particularly expensive in the San Francisco Bay Area.

\section{Air Quality}

Air quality is measured using concentrations of ground level ozone. The right-side map in Figure 1 shows the locations of 210 monitoring stations, which are overlaid on public school districts. Community-specific measures were constructed by first assigning to each house the ozone measure recorded at the nearest monitoring station, and then taking an average over all of the houses in the community. ${ }^{19}$ We repeated this process for 1999, 2000, and 2001, and then averaged the results. The final measure of air quality ranges from 0.031 (parts per million) in the highest air quality community to 0.106 in the lowest.

\footnotetext{
${ }^{18}$ The criterion used to select job/housing location combinations is that they must account for at least 500 working households $(0.02 \%$ of the working population). This effectively excluded multiple-hour commutes between distant locations.

${ }^{19}$ The exact ozone measure used is the average of the top 301 -hour daily maximum readings recorded at each monitoring station during the course of a year.
} 


\section{School Quality}

School quality is defined using California's Academic Performance Index (API), a composite index of standardized test scores, weighted across all subjects and grade levels. For each community, a three-year average API was constructed by weighting the score of each school in the community by its number of students from 1999-2001. The resulting measure ranges from 528 to 941 . A set of community-specific dummy variables are used to capture the composite effect of all other localized amenities on household location choices.

\section{Households and their Housing Location Choices}

Finally, a sample of micro data on households and their location choices were drawn from the U.S. 2000 Census of Population and Housing. Key variables include house location, household income, and the primary earner's job location, occupation, industry, wage income, commute time, gender, age, race, and years of education. ${ }^{20}$ We assumed that if a worker were to move to a different job-house location, his counterfactual commute time would be the average commute time observed for that location. ${ }^{21}$

\footnotetext{
${ }^{20}$ We used the 5\% micro data sample. Occupation is defined using the Standard Occupational Classification system. Industry is defined using the North American Industrial Classification System. Job and house locations are defined in the Census data as public use microdata areas (PUMA). In most cases, there is an exact mapping from PUMAs to PMSAs and unified school districts. In cases where PUMA boundaries overlap with school district boundaries, we assigned households to communities based on the assumption that people are uniformly distributed across PUMAs.

${ }^{21}$ For additional detail on the data and an explanation of the econometric methods used, see Kuminoff (2010).
} 


\section{Defining the Macroeconomic Conditions}

Next, we calibrated the model to reflect the duration of unemployment spells observed in the U.S. Current Population Survey (CPS) 22 at different stages of the business cycle. The CPS provides monthly data on the labor market status of a sample of approximately 60,000 Americans. From these data we constructed a subsample of workers age 16 or older who were unemployed between January 2002 and February 2012. ${ }^{23}$ Then, following Shimer $(2005,2012)$, we constructed an approximation of the job finding rate $\left(\omega_{s, t}\right)$, which indicates the share of workers who were unemployed at date $t$ but found work within $s$ weeks of that date. ${ }^{24}$

We calculate $\omega_{s, t}$ by industry nationwide for a few key time periods. We do not consider geographic variation because job-finding rates for unemployed workers in the San Francisco-Sacramento area are very similar to those for the nation as a whole. There are larger differences in job-finding rates by industry. However, the variations in job-finding rates by geographic area and industry are outweighed by the variation over the course of the business cycle.

Thus, the graphs in Figure 2 show job-finding rates by industry for workers who initially became unemployed in August 2006, January 2008, and December

\footnotetext{
22 The data can be accessed at: http://www.census.gov/cps/data/http://www.census.gov/cps/data/

${ }^{23} \mathrm{We}$ focus on this time period because the industry classifications were consistent over time, enabling us to construct industry-specific job finding rates.

${ }^{24}$ Formally, given the total number of workers unemployed at a date $t, u_{t}$, and the number unemployed for more than $s$ weeks at date $t+s, u_{t+s}^{s}$, we can approximate the job finding rate $\left(\omega_{s, t}\right)$ as: $\omega_{s, t}=1-u_{t+s}^{s} / u_{t}$.
} 
2009, which reflect "expansion", "normal”, and "recession" labor markets. These months had the highest, median, and lowest job-finding rates, respectively, in our CPS sample. Figure 2 clearly indicates that the differences in job-finding rates over the business cycle are much larger than the differences by industry, and that they persist strongly for at least two years. ${ }^{25}$

Our findings are consistent with the earlier work of Hall (2006) and Shimer (2012), who show that variation in the job-finding rate over the business cycle explains most of the fluctuations in unemployment; and Șahin et al. (2012), who show that little of the variation in aggregate unemployment can be explained by variation across geographic regions or industries/occupations. Because variation over the business cycle and the unemployed worker's prior industry seem to be the most important channels, our analysis focuses on these. This allows us to evaluate whether aggregate economic conditions have a significant impact on the estimated welfare costs of job loss from environment regulations.

\section{Summary of Predicted Wage Effects and Welfare Effects of}

\section{Layoffs}

The results of our simulation exercise for Northern California suggest that the net reduction in earnings experienced by a worker who loses his job may significantly

\footnotetext{
${ }^{25}$ Although the CPS indicates that workers should be able to report almost arbitrarily long unemployment spells, we find that almost no workers report spells longer than two years, and that the maximum duration is 124 weeks. Thus, we truncate unemployment duration at two years.
} 
understate the reduction in welfare experienced by that worker's household. In our simulations, the workers who remain in the same houses after losing their jobs tend to experience longer commutes after they relocate to new jobs. Moreover, the workers who move to new housing communities that are closer to their new jobs tend to consume (housing, amenity) bundles that they perceive to be inferior to the bundles at their original locations. The associated reductions in quality of life can substantially affect (and even dominate) the welfare loss that a household experiences when the primary earner is laid off. We find that the importance of reductions in quality of life relative to reductions in earnings varies systematically with household demographics and with workers' industries and job locations.

\section{$\underline{\text { Aggregate Results }}$}

Table 1 presents our aggregate results concerning the wage effects and welfare effects of layoffs. ${ }^{26}$ As shown in Panel A, the wages lost per worker due to temporary unemployment (i.e., during the unemployment spell) ranges from an average of $\$ 15,234$ in our expansion scenario, which has a 4.5 month mean unemployment duration, to an average of $\$ 30,815$ in our recession scenario, which has a 9.4 month mean unemployment duration (see rows 1 and 2). Converting these figures to annuities using the number of expected life years remaining for the

\footnotetext{
${ }^{26}$ All figures in the table are based on iteratively "laying off", one at a time, individuals drawn from a random 1-in-10 sample of Northern California households using the Census Bureau's household weights.
} 
worker and an interest rate of $0.07,{ }^{27}$ we find that the annualized wage loss from temporary unemployment ranges from $\$ 1,231$ to $\$ 2,492$ (row 3).

Panel B reports the average difference in annual salary between workers' new utility maximizing jobs and their old jobs. We consider two scenarios for how layoffs affect employment opportunities. The first row summarizes the best outcome for workers, in which being fired does not diminish their job opportunities. That is, at the end of a worker's unemployment spell, he is simply rehired at his old job (or hired at an identical job in the same location), and there is no change in the worker's salary. The second row reports the change in wages when all workers are forced to move to their second-best job locations. We would expect the average worker to be paid less due to a loss of job-specific or industry-specific human capital. Indeed, annual wages decrease by nearly $\$ 4,000$ for the average worker. This prediction is consistent with evidence from ex post studies of both mass layoffs in general (Couch and Placzek 2010) and layoffs caused specifically by environmental regulation (Walker 2013). The standard deviation on the change in wage (shown in parentheses) is more than three times the mean, in part, because $38 \%$ of workers experience wage increases. The workers who experience wage increases also experience a lower quality of life due to increased commute times or having moved to a less desirable neighborhood.

Finally, Panel $\mathrm{C}$ reports the expected equivalent variation (i.e., the average

\footnotetext{
${ }^{27}$ Expected life years remaining is based on Center for Disease Control life tables for the year 2000, and the interest rate matches the 1995-2005 average interest rate on a fixed rate 30-year home loan.
} 
change in household welfare). ${ }^{28}$ In the "normal" scenario, for example, the range of predictions for expected EV per household per year ranges from $-\$ 1,617$ under the scenario where the worker is rehired at an identical job (row 1 ) to $-\$ 7,300$ in the scenario where the worker has to move to his second best job location (row 2). In the first case, the state of the business cycle is very important for welfare measurement, with a $100 \%$ difference in EV between the recession and expansion scenarios. In contrast, the state of the business cycle is relatively less important when workers have to relocate. In that case, the measures of $\mathrm{EV}$ are driven by changes in salary at the workers' new jobs and changes in utility from moving to different housing communities and different commuting options.

\section{$\underline{\text { Demographic Groups }}$}

Table 2 disaggregates the results by demographic group. For brevity, we only report results for "normal" business cycle conditions here. We find that earnings losses tend to (i) be larger for men relative to women, (ii) increase with experience, and (iii) increase with age. Thus, our qualitative predictions about the changes in earnings due to layoffs are consistent with the stylized facts about demographic variation in the income effects of layoffs summarized by Mansur and Posner (2012). Our intra-urban sorting model is not constrained to reproduce any

\footnotetext{
${ }^{28}$ Recall that EV is the annual payment we would have to make to a group of workers each year for the rest of their lives in order to compensate them for the loss of their most preferred and initially chosen job-house pair. Expected EV is calculated by integrating over the distribution of unemployment spells for each business cycle scenario.
} 
of these results, but the fact that it does reproduce them when applied to the data for Northern California provides some preliminary support for the model's validity. The results also suggest that earnings losses tend to increase with education levels and tend to be larger for homeowners than for renters.

On average, lost earnings are responsible for about three-quarters of the overall loss in welfare. This can be seen by dividing the expected change in real wages (column 3) by the expected EV, (column 4). The remainder of the welfare loss is due to the fact that when the average worker makes a job switch, he chooses either a longer commute or moves to a community with a combination of house prices and local public goods that he finds less desirable (i.e., there a decline in the worker's quality of life). The relative importance of the latter effect varies by gender, age, education, years of experience in the labor force, and homeownership because of differences in the locations these different types of workers chose initially, as well as differences in their preferences and skills.

\section{Earnings and Welfare Effects by Location}

Table 3 reports the earnings losses (column 1) and overall welfare losses due to layoffs (column 2) according to a household's original job location. It also reports the fraction of households that move to a new housing community (column 3) and the fraction of households that experience increases in specific amenities when they move to their new communities (columns 4-8). The table illustrates why the earnings losses in column 1 tend to understate the welfare losses in col- 
umn 2 (as they do here for seven of the eight job locations). The clearest example of this bias is for workers who lose jobs in Sacramento. Sacramento is a relatively low-wage area, so workers who lose jobs there experience relatively modest earnings losses when they relocate (see column 1). However, these earnings losses represent just one-third of their total welfare loss (see column 2), with the remainder of the welfare loss accounted for by changes in living conditions (see columns 4-8). Sacramento offers a combination of house prices and amenities that are low relative to other communities in the Bay Area. By choosing to live in Sacramento initially, households revealed that they preferred this type of community (i.e., that they put a lower weight on public goods and a higher weight on private consumption). The results indicate that when workers in these households find new employment elsewhere in the Bay Area, $78 \%$ of them face a longer commute, $72 \%$ move to a new community with lower school quality, and $68 \%$ pay more for housing, all of which lower their welfare.

The Sacramento example also illustrates a more general implication of the sorting model. The workers who choose to live in "dirty" areas based on relatively weak preferences for environmental quality may experience disproportionate welfare losses if they are effectively forced by a regulation to move to "clean" areas where housing prices and amenities are both higher. This is especially important when considering policies that establish minimum standards on environmental quality, because such policies effectively target the dirtiest areas. 
In contrast to the Sacramento case, earnings losses tend to closely approximate welfare losses for workers who initially worked in the high-wage areas of San Francisco and San Jose. This is because these workers tended to move to areas where they traded off lower air quality and amenities for lower house prices. Although workers generally preferred their former communities, the average cost of this move is smaller than for workers who initially worked in Sacramento.

\section{$\underline{\text { Results for Other Subgroups }}$}

Finally, it is worth noting that our simulation model can be used to examine the implications of job losses for any subgroup of the population that can be identified on the basis of worker and/or household characteristics reported in the Census PUMS data. Subgroups of interest might include the worker's specific industry and occupation, the household's income, house location, and the presence of children in the household. ${ }^{29}$ The next section considers how future evaluations of proposed regulations could use our layoff simulator to examine the potential wage and welfare effects for a small subset of workers in the specific industries, occupations, and metro areas targeted by those regulations.

\footnotetext{
${ }^{29}$ Appendix Table A1 provides an example of this by summarizing the expected EV for households where the primary earner works in the manufacturing sector, by the worker's age and original work location.
} 


\section{IMPLICATIONS FOR EVALUATING SPECIFIC REGULATIONS}

The simulation results presented in the previous section suggest that earnings losses, welfare losses, and the difference between them should not be treated as constants that can simply be transferred from one environmental regulation to another. As we have shown, these statistics vary with the demographic profiles of the workers who lose their jobs, including the industries where they work and the geographic locations of their jobs and houses. Thus, the welfare effects of environmental regulations will generally depend on where the regulations are implemented. This means that analysts must follow several steps in order to use this type of simulation model to evaluate the welfare effects of a specific regulation.

\section{Define Demographic Profiles of Laid Off Workers}

First, the analyst would need to define the demographic profiles of the workers who are laid off. If the evaluation is conducted ex ante, then the layoffs could be based on an estimate from a regulatory agency. ${ }^{30}$ If the evaluation is conducted ex post, then the laid off workers could be identified using data and methods similar to those in Kahn and Mansur (2013), Walker (2013), and Curtis (2013). In

\footnotetext{
${ }^{30}$ Masur and Posner (2012, Table 2) provide examples of agencies that have estimated job losses. Alternatively, one could attempt to develop a new spatially explicit model of firm sorting to predict which industries will be affected and where (in space) the layoffs will occur.
} 
this case, the sorting model would be used to convert these estimates for employment effects into welfare measures.

\section{Define New Job-House Opportunities}

Assuming the analyst knows who will be affected by an environmental regulation, the next step would be to develop a spatial sorting model that describes the affected workers' new job-house opportunities. We have illustrated how this can be done, but there is considerable room for refinement of our model. For example, our baseline model did not allow workers to adjust the number of hours they work, or to look for jobs outside of their SOC 5-digit broad occupation category (e.g., education administrator, detective and criminal investigator, cook). ${ }^{31}$

\section{Incorporate Other Costs and Jobs}

If data on moving costs, job search costs, and job postings are available, then it is possible to refine the sorting model to incorporate this information. To illustrate how this could be done, we have analyzed the sensitivity of our baseline results for Northern California's manufacturing sector to the inclusion of moving costs and job offers in the worker's current PMSA (see Appendix Table 2). Specifically, we assume the annualized cost of moving to a new house is $\$ 681$. This

\footnotetext{
${ }^{31}$ We also ignored moving costs and did not allow laid off workers to search for different jobs in the same labor market. This means that our model is likely to overstate spatial migration.
} 
figure is based on Bieri, Kuminoff, and Pope's (2013) estimate for the annualized physical and financial cost of moving within the Sacramento-San Francisco region. We assume that every laid off worker has the option to move to a new job in the same PMSA but with a wage reduction that ranges from $3 \%$ to $15 \%$. $^{32} \mathrm{We}$ find that migration, expected welfare losses, and the expected change in real wages all increase with the percentage reduction in wages.

For example, when workers in manufacturing jobs are assumed to face a wage reduction of $6 \%$ at their $2^{\text {nd }}$ best job offer in their current PMSA, the average NPV of their lifetime wage reduction is equivalent to $121 \%$ of the current wage (see Appendix Table 2). This is close to the $123 \%$ reduction that Walker (2013) observes for manufacturing workers in four states following implementation of the 1990 Clean Air Act Amendments. Interestingly, the share of workers that the sorting model predicts will move to jobs in new PMSAs (42\%) is also close to the share that Walker observes moving to jobs in new counties (40\%). ${ }^{33}$ Thus, extending our model to include moving costs and job offers in the same PMSA produces results for migration patterns and earnings reductions that are similar to estimates in the literature. In principle, this exercise could be adapted to solve for the percentage reduction in wages that would be required for the model to approximately match the migration patterns and earnings reductions ob-

\footnotetext{
32 This could mean the worker finds a new job at a lower wage in the same PMSA or that the worker is able to negotiate a wage reduction at their old job in order to avoid a layoff. The former mechanism appears to dominate in Walker's (2013) analysis of the Clean Air Act's employment effects in four states.

${ }^{33}$ Four of the PMSAs in our study region include a single county, two PMSAs include two counties, and two include three counties.
} 
served in the data. However, the ideal calibration would also need to be adapted to the relevant geographic area and time period.

\section{CONCLUSIONS}

Over the past decade, full-employment equilibrium models of residential sorting have increasingly been used to evaluate the benefits of existing and proposed environmental regulations in the United States (Sieg et al. 2004, Smith et al. 2004, Walsh 2007, Tra 2010, and Klaiber and Phaneuf 2010). We have demonstrated that these models can be extended to incorporate the welfare effects of job layoffs. Our "layoff simulator" for Northern California's eight major metropolitan areas predicts that the average worker's annual earnings would decline by $\$ 5,553$ if he were to suddenly lose his job during a normal state of the economy and relocate to a new job in one of the seven other metro areas. Approximately $70 \%$ of this reduction is due to a loss of job-specific human capital. The other $30 \%$ comes from wages lost during his unemployment spell. Our layoff simulator predicts that earnings losses account for only $76 \%$ of the change in welfare. The remaining welfare losses come from a job loss effect that has thus far received little attention in the literature: the fact that even after workers find new jobs, they often face a tradeoff between moving to a less desirable community with, for example, lower air quality, or remaining in their current community and having a longer com- 
mute. Our model also predicts that the relative importance of lost earnings and changed housing-commuting options varies systematically across workers according to their age, experience, occupation, industry, job skill, preferences, and geographic location. Thus, our findings suggest that spatial migration has the potential to be of first order importance for evaluating the welfare effects of layoffs. We also find that the state of the economy is important for adjustment costs. Expected earnings losses are approximately $7 \%$ lower during an expansion and $16 \%$ higher during a recession.

Our results suggest that policy analysts should be wary of interpreting changes in workers' earnings as welfare effects of layoffs or newly created jobs. Specifically, the change in earnings fails to account for the welfare implications of: (i) changes in commute time; (ii) changes in housing expenditures; and (iii) changes in access to local public goods. As an extreme case, consider a worker who, prior to a regulation, chose to work at a low paying job in order to live in a desirable community. If the worker loses his job, his next best alternative may be to move to a less desirable community near a higher paying job. If the worker's unemployment spell is brief, his annualized income could increase despite the fact that he is clearly worse off from the move. Our point is that changes in earnings may understate or overstate welfare effects.

Overall, we are optimistic about the potential for using sorting models to evaluate the benefits and costs of environmental regulations that may result in 
layoffs. However, there are limitations to these models and further research and refinements will be needed before they are ready to be widely used for policy analysis.

\section{Model Limitations and Caveats}

As with all revealed preference models of housing and labor markets, our specific predictions for the welfare costs of job losses depend on assumptions about unobserved heterogeneity in preferences and skills among workers and households. Our analysis has several other limitations, which suggests that our results should be interpreted with caution. More specifically, we have ignored forwardlooking behavior and dynamics. Emerging research suggests that these issues are likely to be collectively important for welfare measurement in the sorting literature (e.g. Bishop 2011; Bayer et al. 2011). In particular, being underwater on a mortgage (i.e., owing the bank more than the market value of a house) could make it even more costly for a homeowner to move during a recession, which could reduce mobility and increase the welfare consequences of job loss. In principle, this could be addressed by introducing joint job and housing choices into a dynamic model that treats housing as an investment asset (see e.g., Bayer et al. 2011).

Second, our description of the household adjustment process is simple relative to some articles in the empirical sorting literature (Kuminoff, Smith, and Timmins 
2013) in that we consider a hypothetical policy that is small enough that it will not induce feedback effects of the magnitude that make the general equilibrium features of Rogerson's (2015) model important. For some policies, this may be a fair approximation of reality. For others, it will clearly be insufficient. For example, extremely high unemployment could cause housing prices to fall. This might benefit renters, while reducing the value of homeowners' assets and increasing their probability of foreclosure.

Third, our Northern California model is limited in its geographic scope, covering only $3 \%$ of the U.S. population. Moreover, the basic idea of spatial sorting suggests that the welfare effects of job loss may differ from one metro area to another. This suggests there may be a systematic bias associated with using estimates for wage effects or welfare effects from one geographic area (e.g., a few counties or states) to draw conclusions about wage effects or welfare effects in a different geographic area.

\section{Directions for Future Research}

The sorting literature is an active area of research. Moving forward, one promising approach to using sorting models to systematically assess the effects of prospective regulations would be to develop "regulation simulators" for several metropolitan regions, similar to what we have done for Northern California. A sec- 
ond approach would be to extend the recent work of Bayer, Khan, and Timmins (2011), Bayer et al. (2011), Bieri, Kuminoff, and Pope (2013), Bishop (2011), Kennan and Walker (2011), and Mangum (2012) by developing a national sorting model that integrates unemployment, moving costs, dynamics, imperfect information, and heterogeneous skills and preferences for amenities.

Finally, a key area for future research would be to develop direct evidence on the migration patterns and job transitions of workers who lose their jobs due specifically to environmental regulations. Although aggregate migration data are widely available, it is not clear whether migration patterns systematically differ for workers who lose their jobs. Nor is it clear whether the average unemployment duration is systematically different for workers who lose their jobs due to environmental regulation relative to those who lose their jobs due to all causes. Walker (2013) provides some initial evidence on migration patterns by tracking the job locations of workers in the manufacturing industry who relocated within four states, finding that more than $40 \%$ of workers who were laid off moved to new jobs in different counties. However, it is not clear how many of these workers moved to new houses. Similarly, the work of Mangum (2012), who developed an "islands" model of metropolitan areas with unemployment, raises the question of whether unemployed workers move to new metro areas before or after finding a job there. More generally, if the share of unemployed workers who move to new housing communities and labor markets is small, then a model of only labor 
market sorting might be more useful than a dual-market model of sorting across the housing and labor markets. If the share is large but most movers stay within the same metro area, then a regional model of both markets-similar to the one we have presented here-may be the most appropriate approach. Moreover, if the share of workers who move cross-country is large, then the development of a national sorting model may be the most important and productive direction for future research.

\section{REFERENCES}

Bartik, Timothy J. 2015. "The Social Value of Job Loss and its Effect on the Costs of U.S. Environmental Regulations." Review of Environmental Economics and Policy. [Typesetter - please insert correct citation/title information; this article is part of the same symposium]

Bayer, Patrick, Nathaniel Keohane, and Christopher Timmins. 2009. "Migration and Hedonic Valuation: The Case of Air Quality." Journal of Environmental Economics and Management, 58(1): 1-14.

Bayer, Patrick., Shakeeb. Khan, and Christopher Timmins. 2011. "Nonparametric Identification and Estimation in a Roy Model with Common Nonpecuni- 
ary Returns.” Journal of Business and Economic Statistics, 29(2): 201215.

Bayer, Patrick, Robert McMillan, Alvin Murphy, and Christopher Timmins. 2011. "A Dynamic Model of Demand for Houses and Neighborhoods." NBER Working Paper \#17250.

Bayer, Patrick, and Christopher Timmins. 2005. "On the Equilibrium Properties of Locational Sorting Models.” Journal of Urban Economics 57(3): 46277.

Bieri, David, Nicolai V. Kuminoff, and Jaren C. Pope. 2013. "National Expenditures on Local Amenities.” Working Paper.

Bishop, Kelly. 2011. “A Dynamic Model of Location Choice and Hedonic Valuation." Working Paper.

Couch, Kenneth A. and Dana W. Placzek. 2010. "Earnings Losses of Displaced Workers Revisited." American Economic Review. 100(1): 572-589.

Curtis, Mark. 2013. "Who Loses Under Power Plant Cap-and-Trade Programs?" Working paper.

Epple, Dennis and Holger Sieg. 1999. "Estimating Equilibrium Models of Local Jurisdiction." Journal of Political Economy, 107(4): 645-81. 
Hall, Robert E. 2006. "Job Loss, Job Finding and Unemployment in the U.S.

Economy Over the Past 50 Years.” NBER Macroeconomics Annual 2005, edited by Mark Gertler and Kenneth Rogoff. MIT Press.

Kennan, J. and J.R. Walker. 2011. "The Effect of Expected Income on Individual Migration Decisions.” Econometrica, 79(1): 211-251.

Klaiber, H. Allen and Daniel J. Phaneuf. 2010. "Valuing Open Space in a Residential Sorting Model of the Twin Cities.” Journal of Environmental Economics and Management, 60(2): 57-77.

Kuminoff, Nicolai V. 2010. "Partial Identification of Preferences from a DualMarket Sorting Equilibrium.” Working Paper.

Kuminoff, Nicolai V., V. Kerry Smith, and Christopher Timmins. 2013. "The New Economics of Equilibrium Sorting and Policy Evaluation Using Housing Markets.” Journal of Economic Literature, 51(4): 1007-1062.

Kuminoff, Nicolai V., Todd Schoellman, and Christopher Timmins. 2013. "Can Sorting Models Help us Evaluate the Employment Effects of Environmental Regulations." Paper prepared for the EPA Workshop on Advancing the Theory and Methods for Assessing Employment Effects of Environmental Regulations. 
http://yosemite.epa.gov/ee/epa/eerm.nsf/vwRepNumLookup/EE-

0572?OpenDocument

Mangum, Kyle. 2012. “A Dynamic Model of Cities and Labor Market Development." Working Paper.

Masur, Jonathan S. and Eric A. Posner. 2012. "Regulation, Unemployment, and Cost-Benefit Analysis." Virginia Law Review, 98: 579-634.

Noonan, Mary C. and Jennifer L. Glass. 2012. "The Hard Truth about Telecommuting." Monthly Labor Review, Bureau of Labor Statistics. June: 38-45.

Roback, Jennifer. 1982. "Wages, Rents, and the Quality of Life." Journal of Political Economy, 90(6): 1257-1278.

Rogerson, Richard. 2015. “A Macroeconomic Perspective on Evaluating Environmental Regulations." Review of Environmental Economics and Policy. [Typesetter - please insert correct citation/title information; this article is part of the same symposium]

Rosen, Sherwin. 1979. "Wage Based Indices of Urban Quality of Life.” In Mieszkowski and Straszheim (eds.), Current Issues in Urban Economics.

Roy, A.D. 1954. "Some Thoughts on the Distribution of Earnings." Oxford Economic Papers, 3(2): 135-146. 
Șahin, Ayșegül, Joseph Song, Giorgio Topa, and Giovanni L. Violante. 2012. "Mismatch Unemployment." Working Paper.

Sieg, Holger, V. Kerry Smith, H. Spencer Banzhaf, and Randy Walsh. 2002. "Interjurisdictional Housing Prices in Location Equilibrium." Journal of Urban Economics, 52(1): 131-53.

Sieg, Holger, V. Kerry Smith, H. Spencer Banzhaf, and Randy Walsh. 2004. "Estimating the General Equilibrium Benefits of Large Changes in Spatially Delineated Public Goods." International Economic Review, 45(4): 104777.

Shimer, Robert. 2005. "The Cyclical Behavior of Equilibrium Unemployment and Vacancies." American Economic Review. 95(1): 25-49.

Shimer, Robert. 2012. "Reassessing the Ins and Outs of Unemployment." Review of Economic Dynamics. 15(2): 127-148.

Smith, Kerry. 2015 "Should Benefit-Cost Methods Take Account of High Unemployment? Symposium Introduction.” Review of Environmental Economics and Policy. [Typesetter - please insert correct citation/title information; this article is part of the same symposium]

Smith, V. Kerry, Holger Sieg, H. Spencer Banzhaf, and Randy Walsh. 2004. 
"General Equilibrium Benefits for Environmental Improvements: Projected Ozone Reductions under EPA's Prospective Analysis for the Los Angeles Air Basin." Journal of Environmental Economics and Management, 47(3): 559-84.

Tra, Constant I., 2010. “A Discrete Choice Equilibirum Approach to Valuing Large Environmental Changes." Journal of Public Economics, 94 (1-2): 183-196.

Walker, W. Reed. 2013. "The Transitional Costs of Sectoral Reallocation: Evidence from the Clean Air Act and the Workforce." Quarterly Journal of Economics, 128(4): 1787-1835.

Walsh, Randall L. 2007. "Endogenous Open Space Amenities in a Locational Equilibrium." Journal of Urban Economics, 61(2): 319-44. 
Census tracts overlaid on primary metropolitan areas

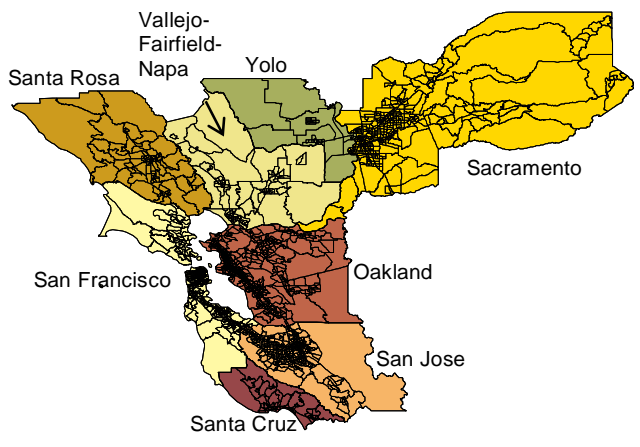

Air quality monitoring stations overlaid on public school districts

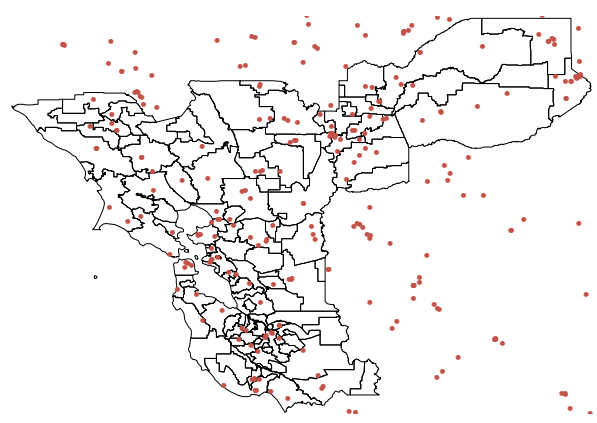

Figure 1: San Francisco and Sacramento Consolidated Metro Areas.

Source: authors' calculations. 


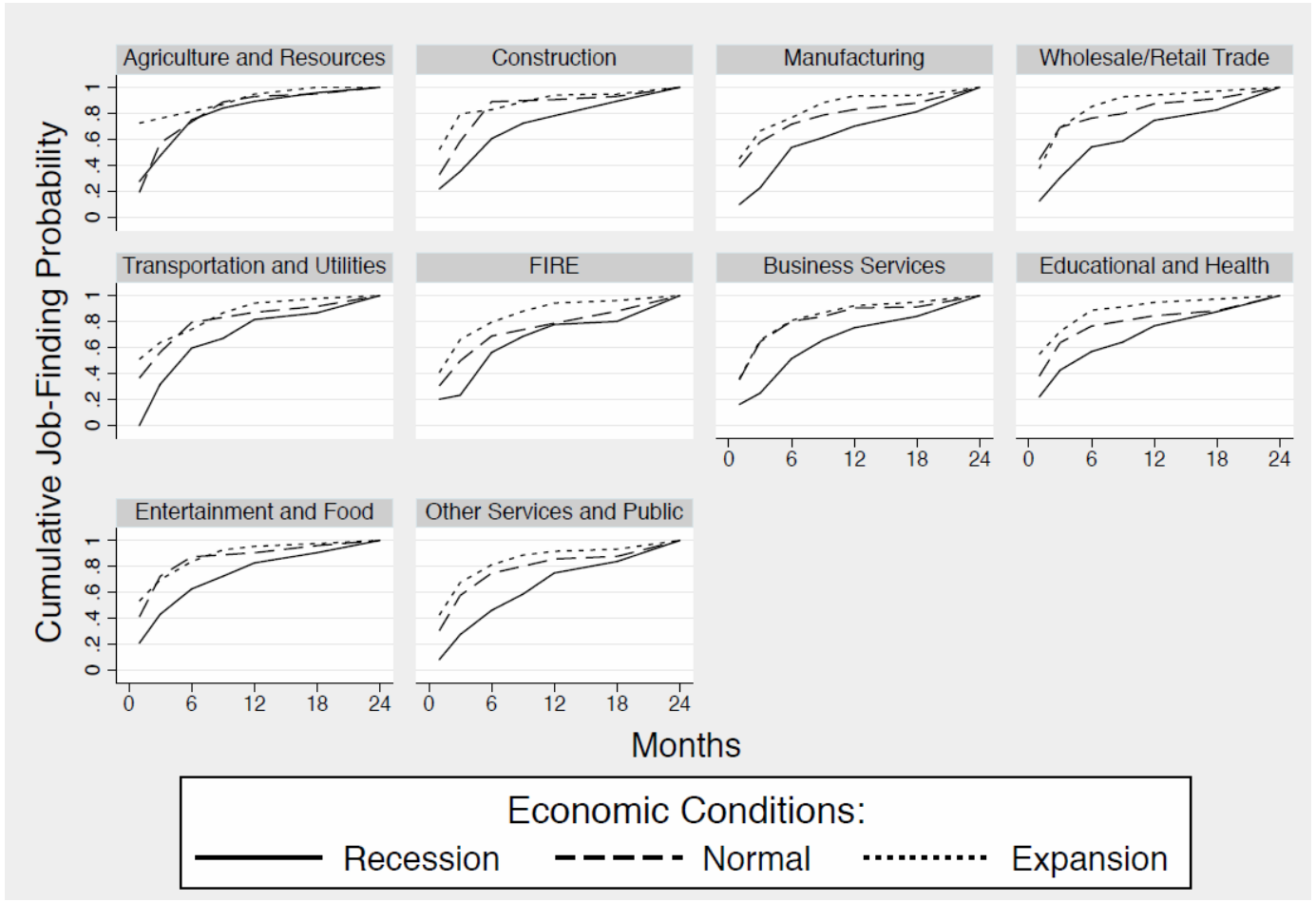

Figure 2: Cumulative Job Finding Probability, by Industry and Business Cycle

Note: These graphs display national cumulative job finding probabilities, by NAICS industry, for workers who were newly unemployed during expansion (Aug 2006), recession (Dec 2009), and normal (Jan 2008) periods. Job finding probabilities were estimated from data on unemployed workers in monthly CPS. In $1.6 \%$ of industry/month combinations, the estimated marginal job finding probability is negative due to sampling error. In these cases we use linear interpolation to restrict the job finding probability to be positive. Some 2-digit industries were aggregated to reduce sampling error. Specifically, Agriculture and Natural Resources $=11,21$; Manufacturing $=31-33$; Wholesale/Retail Trade $=42,44,45$; Transportation and Utilities $=22,48,49 ;$ FIRE $=$ Finance and Insurance (52) and Real Estate and Rental and Leasing (53); Business Services $=54-56 ;$ Education and Health $=61-62 ;$ Entertainment and Food $=71-72 ;$ and Other Services $=51,81,92$.

Sources: authors' calculations. 
Table 1: Annual Wage and Welfare Effects of Simulated Layoffs in Northern California, per Household (year 2000 US dollars)

\begin{tabular}{lcccc}
\hline \hline A. TEMPORARY UNEMPLOYMENT & & & \\
\hline & $\underline{\text { expansion n}}$ & normal & recession \\
Mean unemployment duration (months) & 4.60 & 6.14 & 9.41 \\
Net wages lost during unemployment period (mean per worker) & $-15,234$ & $-19,973$ & $-30,815$ \\
Annualized net wage loss (mean per worker) & $-1,231$ & $-1,617$ & $-2,492$ \\
\hline
\end{tabular}

B. CHANGE IN ANNUAL SALARY

\begin{tabular}{lcccc}
\hline Assumption about New Job & expansion & normal & recession \\
\cline { 5 - 6 } Rehired at identical job in original location & 0 & 0 & 0 \\
Move to 2nd best (job, house) location & $-3,936$ & $-3,936$ & $-3,936$ \\
& $(14,621)$ & $(14,621)$ & $(14,621)$ \\
\hline
\end{tabular}

C. EXPECTED EQUivalent VARIATION

\begin{tabular}{lcccc}
\hline Assumption about New Job & expansion & normal & recession \\
\cline { 5 - 6 } Rehired at identical job in original location & $-1,231$ & $-1,617$ & $-2,492$ \\
Move to 2nd best (job, house) location & $-7,000$ & $-7,300$ & $-7,949$ \\
& $(12,383)$ & $(12,579)$ & $(13,146)$ \\
\hline
\end{tabular}

Notes: The first row of panel A summarizes the mean unemployment duration for the three scenarios shown in Figure 2. The second row reports the wages foregone during the unemployment period for the average worker, net of unemployment insurance. Workers are assumed to collect unemployment insurance at $36 \%$ of the old wages. Row 3 converts the total loss to an annuity, using the worker's expected life years remaining and an interest rate of $7 \%$. Row 2 of Panel B reports the mean change in wage from moving to the worker's second best job. Panel $\mathrm{C}$ reports the expected equivalent variation, taking into account the unemployment spell along with changes in wage and job-house location. The numbers in parentheses are standard errors.

Source: authors' calculations. 
Table 2: Wage and Welfare Effects of Layoffs, by Demographic Group (year 2000 US dollars)

\begin{tabular}{|c|c|c|c|c|}
\hline & (1) & (2) & (3) & (4) \\
\hline & $\begin{array}{l}\text { Annual wage } \\
\text { loss from } \\
\text { temporary } \\
\text { unemployment }\end{array}$ & $\begin{array}{l}\text { Mean change } \\
\text { in annual } \\
\text { salary }\end{array}$ & $\begin{array}{c}\text { Expected } \\
\text { change in real } \\
\text { wages (i.e., } \\
(1)+(2))\end{array}$ & $\begin{array}{c}\text { Expected } \\
\text { equivalent } \\
\text { variation }\end{array}$ \\
\hline Population & $-1,617$ & $-3,936$ & $-5,553$ & $-7,300$ \\
\hline \multicolumn{5}{|l|}{ Gender } \\
\hline women & $-1,293$ & $-2,398$ & $-3,691$ & $-5,594$ \\
\hline men & $-1,810$ & $-4,845$ & $-6,656$ & $-8,318$ \\
\hline \multicolumn{5}{|l|}{ Age } \\
\hline under 40 & $-1,305$ & $-2,821$ & $-4,126$ & $-5,961$ \\
\hline $40-60$ & $-1,850$ & $-4,908$ & $-6,757$ & $-8,431$ \\
\hline over 60 & $-2,063$ & $-4,313$ & $-6,376$ & $-8,139$ \\
\hline \multicolumn{5}{|l|}{ Education } \\
\hline less than 13 years & -978 & $-2,377$ & $-3,355$ & $-4,695$ \\
\hline $13-16$ years & $-1,312$ & $-2,762$ & $-4,075$ & $-5,738$ \\
\hline more than 16 years & $-2,154$ & $-5,550$ & $-7,704$ & $-9,724$ \\
\hline \multicolumn{5}{|l|}{ Experience } \\
\hline less than 10 years & $-1,113$ & $-1,701$ & $-2,814$ & $-4,893$ \\
\hline $10-20$ years & $-1,614$ & $-4,213$ & $-5,827$ & $-7,529$ \\
\hline more than 20 years & $-1,791$ & $-4,538$ & $-6,329$ & $-7,997$ \\
\hline \multicolumn{5}{|l|}{ Homeownership } \\
\hline renters & $-1,163$ & $-1,989$ & $-3,151$ & $-5,043$ \\
\hline owners & $-1,909$ & $-5,177$ & $-7,086$ & $-8,748$ \\
\hline
\end{tabular}

Note: Column 1 reports the wage loss from temporary unemployment, converted to an annuity using each worker's age and life-year tables for the year 2000 from the Center for Disease Control. The annualized loss reflects an expectation over the distribution of unemployment durations corresponding to the job finding probability distribution during "normal" labor market conditions. Column 2 reports the mean change in annual salary when workers move to their second best job locations.

Source: authors' calculations. 
Table 3: Wage and Welfare Effects of Layoffs, by Original Job Location

\begin{tabular}{|c|c|c|c|c|c|c|c|c|}
\hline \multirow[b]{3}{*}{ Job Location in 2000} & (1) & (2) & \multirow{3}{*}{$\begin{array}{l}\text { Share } \\
\text { moving to } \\
\text { different } \\
\text { community }\end{array}$} & (4) & (5) & (6) & (7) & (8) \\
\hline & $\begin{array}{l}\text { Expected } \\
\text { change in } \\
\text { real wages }\end{array}$ & $\begin{array}{c}\text { Expected } \\
\text { equivalent } \\
\text { variation }\end{array}$ & & \multicolumn{5}{|c|}{ Share experiencing an increase in: } \\
\hline & (year 2000 & US dollars) & & $\begin{array}{c}\text { housing } \\
\text { price }\end{array}$ & $\begin{array}{c}\text { air } \\
\text { quality }\end{array}$ & $\begin{array}{l}\text { school } \\
\text { quality }\end{array}$ & $\begin{array}{l}\text { commute } \\
\text { time }\end{array}$ & $\begin{array}{l}\text { other } \\
\text { public } \\
\text { goods }\end{array}$ \\
\hline Northern California & $-5,552$ & $-7,300$ & 0.94 & 0.27 & 0.42 & 0.55 & 0.59 & 0.26 \\
\hline Oakland & $-5,443$ & $-6,706$ & 0.94 & 0.22 & 0.31 & 0.59 & 0.57 & 0.24 \\
\hline Sacramento & $-2,579$ & $-7,450$ & 0.91 & 0.68 & 0.83 & 0.28 & 0.78 & 0.67 \\
\hline San Francisco & $-6,418$ & $-7,544$ & 0.93 & 0.12 & 0.20 & 0.63 & 0.46 & 0.15 \\
\hline San Jose & $-7,348$ & $-8,188$ & 0.96 & 0.13 & 0.46 & 0.58 & 0.52 & 0.08 \\
\hline Santa Cruz & $-6,976$ & $-5,896$ & 1.00 & 0.17 & 0.61 & 0.80 & 0.78 & 0.11 \\
\hline Santa Rosa & $-5,687$ & $-5,850$ & 1.00 & 0.27 & 0.30 & 0.68 & 0.73 & 0.27 \\
\hline Vallejo & $-3,786$ & $-6,130$ & 0.93 & 0.34 & 0.31 & 0.48 & 0.79 & 0.37 \\
\hline Yolo & $-3,649$ & $-6,482$ & 0.90 & 0.55 & 0.72 & 0.57 & 0.78 & 0.44 \\
\hline
\end{tabular}

Note: Columns 1 and 2 report the same measures of the expected changes in real wages and EV as in Table 2. Column 3 reports the share of workers who are predicted to move to a different housing community after finding a new job in a different PMSA. Columns 4 through 8 report the share of households experiencing increases in housing prices, air quality, school quality, unobserved public goods, and commute times after moving to their new locations.

Source: authors' calculations. 
Appendix Table 1: Wage and Welfare Effects of Layoffs in the Manufacturing Sector (year 2000 dollars)

\begin{tabular}{|c|c|c|c|c|}
\hline & & $\begin{array}{c}\text { Expected } \\
\text { change in real } \\
\text { wages }\end{array}$ & $\begin{array}{c}\text { Expected } \\
\text { equivalent } \\
\text { variation }\end{array}$ & $\begin{array}{c}\text { Share of } \\
\text { manufacturing } \\
\text { workers }\end{array}$ \\
\hline All Manufacturing & & $-7,773$ & $-8,828$ & 1.00 \\
\hline Job Location in 2000 & Age & & & \\
\hline \multirow{2}{*}{ Oakland } & under 40 & $-5,329$ & $-6,283$ & 0.09 \\
\hline & over 40 & $-7,419$ & $-8,445$ & 0.12 \\
\hline \multirow{2}{*}{ Sacramento } & under 40 & $-2,667$ & $-7,953$ & 0.05 \\
\hline & over 40 & $-6,104$ & $-12,290$ & 0.05 \\
\hline \multirow{2}{*}{ San Francisco } & under 40 & $-5,073$ & $-6,565$ & 0.06 \\
\hline & over 40 & $-8,986$ & $-9,447$ & 0.06 \\
\hline \multirow{2}{*}{ San Jose } & under 40 & $-7,382$ & $-8,092$ & 0.21 \\
\hline & over 40 & $-11,336$ & $-11,132$ & 0.26 \\
\hline \multirow{2}{*}{ Santa Cruz } & under 40 & $-8,660$ & $-7,050$ & 0.01 \\
\hline & over 40 & $-8,525$ & $-6,535$ & 0.01 \\
\hline \multirow{2}{*}{ Santa Rosa } & under 40 & $-3,988$ & $-4,191$ & 0.02 \\
\hline & over 40 & $-7,784$ & $-7,677$ & 0.02 \\
\hline \multirow{2}{*}{ Vallejo } & under 40 & $-4,558$ & $-6,124$ & 0.01 \\
\hline & over 40 & $-7,141$ & $-9,019$ & 0.02 \\
\hline \multirow{2}{*}{ Yolo } & under 40 & $-1,562$ & $-4,568$ & 0.01 \\
\hline & over 40 & $-6,019$ & $-9,530$ & 0.01 \\
\hline
\end{tabular}

Note: See the text and notes to tables 1-3 for definitions of the variables in each column.

Source: authors' calculations. 
Appendix Table 2: Sensitivity Analysis: Adding Moving Costs and Job Offers in the Same PMSA for Workers in the Manufacturing Sector

\begin{tabular}{cccccc}
\hline \hline $\begin{array}{c}(1) \\
\text { \% reduction }\end{array}$ & $(2)$ & $(3)$ & $(4)$ & $(5)$ & $(6)$ \\
in wage at \\
$\begin{array}{c}\text { 2nd best job } \\
\text { in same } \\
\text { PMSA }\end{array}$ & $\begin{array}{c}\text { Expected } \\
\text { change in } \\
\text { real wages }\end{array}$ & $\begin{array}{c}\text { Expected } \\
\text { equivalent } \\
\text { variation }\end{array}$ & $\begin{array}{c}\text { Share } \\
\text { moving to } \\
\text { different } \\
\text { community }\end{array}$ & $\begin{array}{c}\text { Share } \\
\text { moving to } \\
\text { job in } \\
\text { different } \\
\text { PMSA }\end{array}$ & $\begin{array}{c}\text { NPV } \Delta \text { wage } \\
\text { / wage }\end{array}$ \\
\hline $3 \%$ & $-3,662$ & $-4,058$ & 0.24 & 0.20 & -0.98 \\
$6 \%$ & $-4,742$ & $-5,259$ & 0.52 & 0.42 & -1.21 \\
$9 \%$ & $-5,558$ & $-6,141$ & 0.70 & 0.57 & -1.36 \\
$12 \%$ & $-6,143$ & $-6,804$ & 0.79 & 0.68 & -1.46 \\
$15 \%$ & $-6,563$ & $-7,306$ & 0.84 & 0.77 & -1.52 \\
-- & $-7,773$ & $-8,828$ & 0.96 & 1.00 & -1.44 \\
\hline
\end{tabular}

Note: Columns 2 through 4 report the same measures of the expected changes in real wages, EV, and share moving to a different community as Table 3. Column 5 reports the share of workers who are predicted to move to a new job in a different PMSA, given that they can find a new job in the same PMSA at the \% reduction in wage given in column (1). Column 6 reports the net present value of the annualized reduction in wages as a fraction of the worker's baseline wage, assuming that workers under 62 will retire at age 62 . All but the last row include an annualized moving cost of $\$ 681$. The last row corresponds to the baseline model from Table 3 that assumes free mobility and no job offers in the worker's original PMSA.

Source: authors' calculations 